REVISTA CIENCIAS BIOMÉ DICAS

ÉTICA, BIOÉTICA Y HUMANISMO

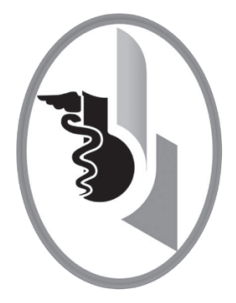

\title{
REFLEXIONES SOBRE LOS VALORES DEL PROGRAMA DE MEDICINA DE LA UNIVERSIDAD DE CARTAGENA $(*)$
}

\author{
REFLECTION ON VALUES OF THE FACULTY OF MEDICINE AT \\ UNIVERSITY OF CARTAGENA
}

Milanés Pérez Rosa ${ }^{1}$

Correspondencia: rmilanesp@unicartagena.edu.co

Recibido para evaluación: noviembre - 28 - 2010. Aceptado para publicación: febrero - 10-2011

\section{RESUMEN}

Los valores de un programa son los postulados éticos que deben regir los currículos y todas las actividades de los directivos, docentes y estudiantes. Se hace una reflexión acerca de los valores de Facultad de Medicina de la Universidad de Cartagena, se explicita su significado y se hace énfasis en la importancia de su interiorización y aplicación en los diversos procesos de la vida del programa, en especial en el quehacer de los individuos que la representan. Rev.cienc.biomed. 2011; 2(1): 154-157

\section{PALABRAS CLAVES}

Valores. Ética médica. Currículo.

\section{SUMMARY}

The values of a program are the ethical principles that should guide the curriculum and all activities of managers, professors and students. In this paper I reflect on values of our faculty, explain their meaning and emphasize the importance of their internalization and implementation in various processes of the program, especially in the work of individuals that represent our faculty. Rev.cienc.biomed. 2011; 2(1): 154-157

\section{KEYWORDS}

Values. Medical ethics. Curriculum.

\begin{abstract}
"Una generación podría transformar al mundo, dando nacimiento a otra generación de niños valientes, no retorcidos en formas antinaturales, sino rectos y cándidos, generosos, afectuosos y libres. Su ardor barrería la crueldad y el dolor que hoy soportamos sólo por ser perezosos, cobardes, duros de corazón y estúpidos. Es la educación la que nos ha dado estas malas cualidades, y es la educación quien debe promover las virtudes opuestas. La Educación es la llave del nuevo mundo."
\end{abstract}

Bertrand Russell

\footnotetext{
* Producto del taller de formación en escritura científica realizado por el Departamento de Investigaciones de la Facultad de Medicina de la Universidad de Cartagena. Colombia.

1 Médico. Especialista en Otorrinolaringología. Docente Departamento Quirúrgico. Ex- vicedecana Curricular. Presidente Comité de Currículo 2008-2010. Facultad de Medicina. Universidad de Cartagena. Colombia.
} 


\section{INTRODUCCIÓN}

Están definidos los valores que deben enmarcar las diferentes actuaciones de los integrantes del Programa de Medicina de la Universidad de Cartagena. Expresan su importancia al determinar la ideología central del Programa, para así sentar las bases para el desarrollo de todos sus procesos. Se esbozan algunas recomendaciones para su socialización y resalta la pertinencia de los mismos en lo que debe ser el quehacer médico.

\section{LA EDUCACIÓN Y LOS VALORES}

El proceso educativo encierra una dimensión teleológica, es decir, encierra una finalidad constitutiva y esencial en todo proceso educativo. Pero la educación debe encerrar además una necesaria referencia a valores. No hay proceso educativo sin referencia a valores, la educación consiste en principio, en una formación en valores del individuo, orientándolo hacia adecuadas ideas y comportamientos sociales, ideológicos y morales. En este contexto, las escuelas de Medicina deben cultivar valores que determinen la humanización de sus estudiantes y los dirijan hacia una conducta ética y profesional adecuada en beneficio de la práctica médica.

Los valores se han definido como cualidades de las personas, las cosas, las instituciones y los sistemas, que permiten acondicionar el mundo y hacerlo habitable. Son principios de orientación de la conducta humana, que enlazan las inclinaciones y las aspiraciones del espíritu y que serían las bases de las actitudes y de las normas.

Son los valores los que permiten definir las aspiraciones de las Instituciones Educativas y por lo tanto, es en ellos, en donde hay que encontrar la fuente primera de los Proyectos Educativos Institucionales (PEI), de los Proyectos Educativos de los Programas (PEP) y del currículo. En el sentido educativo, el currículo, es el diseño que permite planificar las actividades académicas. Mediante la construcción curricular la Institución plasma su concepción de educación. De esta manera, el currículo permite la previsión de las cosas que hemos de hacer para posibilitar la formación de los educandos.

La ideología central de una Institución o Programa comprende los propósitos y los valores, que guían e inspiran a todos los integrantes de la organización; conjunto de preceptos básicos que condensa lo que somos y lo que representamos; que por lo tanto deben ser evidentes, reconocidos y puestos en práctica por los integrantes de la comunidad.

Los valores de un programa deben ser comunicados, socializados y discutidos continuamente por la comunidad y además estar siempre de fondo, por ejemplo, en cursos de inducción y de orientación de estudiantes, entrevistas de personal, en los lineamientos curriculares, esto para resguardar el equilibrio y la honestidad del personal que más allá del conocimiento académico y científico, también transmite enseñanzas morales y sociales a los educandos, mediante actos, comportamientos, opiniones y puntos de vista.

Parra señala que "el docente universitario debe ser modelo como persona íntegra, conocer las normas que definen la identidad de la Universidad y las formas de relación que se dan en ella, tener disposición para reconocer la dimensión ética y actuar siguiendo una ética universalista, ser ejemplo de comportamiento ético y social coherente con los valores propugnados y tener la capacidad para transferirlos a sus estudiantes procurando seguir y observar las mejores normas científicas y éticas conocidas para su disciplina".

Debido a la crisis de valores tradicionales, factores socioculturales, paradigmas equivocados y tantas situaciones preocupantes, se ha invocando a la ética y la bioética dentro de los planes de estudios en los programas de Medicina, como un eje curricular indispensable para la formación de su producto educativo. Se trata de establecer por tanto la comunión con uno de los propósitos del Programa de Medicina para la formación de los estudiantes: "Velar para que el estudiante en lo personal y en lo 
profesional se desempeñe en un marco ético y bioético".

Según Monterrosa "en el proceso educativo las consideraciones de tipo axiológico deben ir de la mano de las de tipo profesional. Los aspectos éticos deben ir de la mano de la pedagogía. Las consideraciones éticas deben ser punta de lanza para la estructuración de una nueva generación de ciudadanos enriquecidos en preceptos axiológicos, capacitados profesional y éticamente para movilizar al país hacia el centro de procesos de desarrollo científico y social de escala y trascendencia mundial. Lo ético no debe ser una asignatura o un programa, lo ético debe ser una parte del quehacer diario, cotidiano, una forma de acción en la vida y para la vida, una estrategia válida y provechosa para luchar y prevenir la corrupción. En síntesis, la ética es tan central como la ciencia, en la consolidación de una formación universitaria integral".

En el caso de la educación médica, la enseñanza que se imparte debe ir encaminada a promover el servicio médico con responsabilidad social para contribuir al mejoramiento de la calidad de vida y las condiciones de salud de la sociedad. Esto es urgente hoy, cuando la enseñanza de la Medicina debe retomar sus fuertes principios éticos y su gran ideal de vocación de servicio, para hacer frente a factores externos, como el sistema de salud, que han devaluado la ideología del profesional de la salud, alejándolo del compromiso y la vocación de servicio social.

\section{LOS VALORES DE UN PROGRAMA DE FORMACIÓN MÉDICA}

El Programa de Medicina de la Universidad de Cartagena involucra en su Proyecto Educativo valores institucionales que sirven de marco de referencia para orientar los procesos académicos y administrativos que intervienen en la formación del médico y que además son fundamentales para el desempeño de esta profesión. Estos valores son los siguientes:

- RESPETO: por la vida, la dignidad humana y la autonomía individual. Respeto por la diversidad cultural y del pluralismo. Todas las personas son iguales en valor y dignidad. En los ámbitos académicos y asistenciales no habrá discriminación de personas por edad, género, raza, credo religioso o político. Respeto y protección del medio ambiente, la biosfera, y la biodiversidad.

- HONESTIDAD: es una cualidad de calidad humana que consiste en comportarse y expresarse con coherencia y sinceridad (decir la verdad), de acuerdo con los valores de verdad y justicia. Honestidad en el quehacer como ciudadano, docente, estudiante, médico, investigador y gestor del desarrollo.

- SERVICIO: contribuir al mejoramiento de las condiciones de vida, educación, y salud de toda la población.

- RESPONSABILIDAD: actuar con un claro concepto para el cumplimiento del fin encomendado. Responsabilidad en la formación de médicos idóneos y generosidad en la transmisión del conocimiento. Formación integral de médicos agentes de cambio en sus comunidades.

- SOLIDARIDAD: colocar el conocimiento científico, tecnológico, humanístico y cultural al servicio de la solución de los desafíos y complejidades de la sociedad

- TRASCENDENCIA: reconocimiento de que nuestra vida plena se inserta en procesos más amplios de espacio y tiempo, a la luz de los cuales adquiere sentido de dirección, gozo y liberación. Nos da con ello la esperanza que podemos lograr un mundo mejor, de que nuestros esfuerzos por lograrlo no serán en vano.

- ESPIRITUALIDAD: es la necesidad consciente de Dios. Nuestra vida espiritual establece firme y seguramente las bases de la unidad en la diversidad. La espiritualidad le revela al ser el sentido de su vida y el significado de su existencia en la tierra.

De estos siete valores se destacan el respeto y la honestidad como los máximos principios que debemos inculcar y practicar. El respeto, por la vida, por la naturaleza, por la dignidad y el derecho del otro, debe ser el principio rector de toda profesión. Sin este valor del cual se deriva la tolerancia no 
pueden existir relaciones sociales armoniosas y por ende convivencia pacífica. En cuanto a la honestidad, es un valor a rescatar y reafirmar, sobre todo en nuestros contextos sociales, donde se ve al honesto como tonto y por el contrario se pondera al avivato. Respeto y honestidad deben ser los motores para avanzar hacia una dinámica de justicia social y equidad.

Por ejemplo, como resultado del compromiso profesional con sus pacientes, enmarcados en el respeto y la honestidad, los médicos están obligados a actuar sólo en beneficio de aquellos y así propender por el uso racional de exámenes y medicamentos. El médico no sólo debe ser honesto, sino digno de confianza y por ello siempre debe actuar en forma transparente, evitando cualquier actividad que pueda comprometer su autonomía profesional u originar situaciones con conflicto de intereses utilitaristas o comerciales.

\section{CONCLUSIÓN}

Es necesario insistir, primero, en que la función social de las instituciones educativas y sobre todo de los docentes es dar una formación integral a las nuevas generaciones; segundo, el perfil de los nuevos docentes debe acercarse a los lineamientos de valores institucionales, puesto que ellos tendrán la responsabilidad de formar futuras generaciones de médicos, de crear un mejor futuro para la sociedad; tercero, los valores del programa de Medicina requieren ser socializados a todos sus integrantes y deben ser reglas de conducta especialmente de todos los miembros directivos y docentes de la comunidad, ya que con su ejemplo modelarán la correcta apropiación de los mismos por los estudiantes, futuros egresados.

CONFLICTOS DE INTERÉS: ninguno que declarar.

\section{LECTURAS RECOMENDADAS}

1. Lepeley María Teresa. Gestión y Calidad en Educación. McGraw-Hill Interamericana, 2001.

2. Monterrosa Castro Álvaro, Docencia Universitaria Reflexiones. 1999

3. Olivera Díaz Álvaro, Relato "En el mundo de los valores". Revista Ciencias Biomédicas 2010; 1(1): 117 - 121.

4. Parra Chacón Edgar. Mediadores cognitivos en educación superior. Universidad de Cartagena. Colombia. 2006

5. Proyecto Educativo del Programa de Medicina. Facultad de Medicina. Universidad de Cartagena. Colombia. 2009.

6. Proyecto Educativo Institucional. Universidad de Cartagena. Colombia. 2009

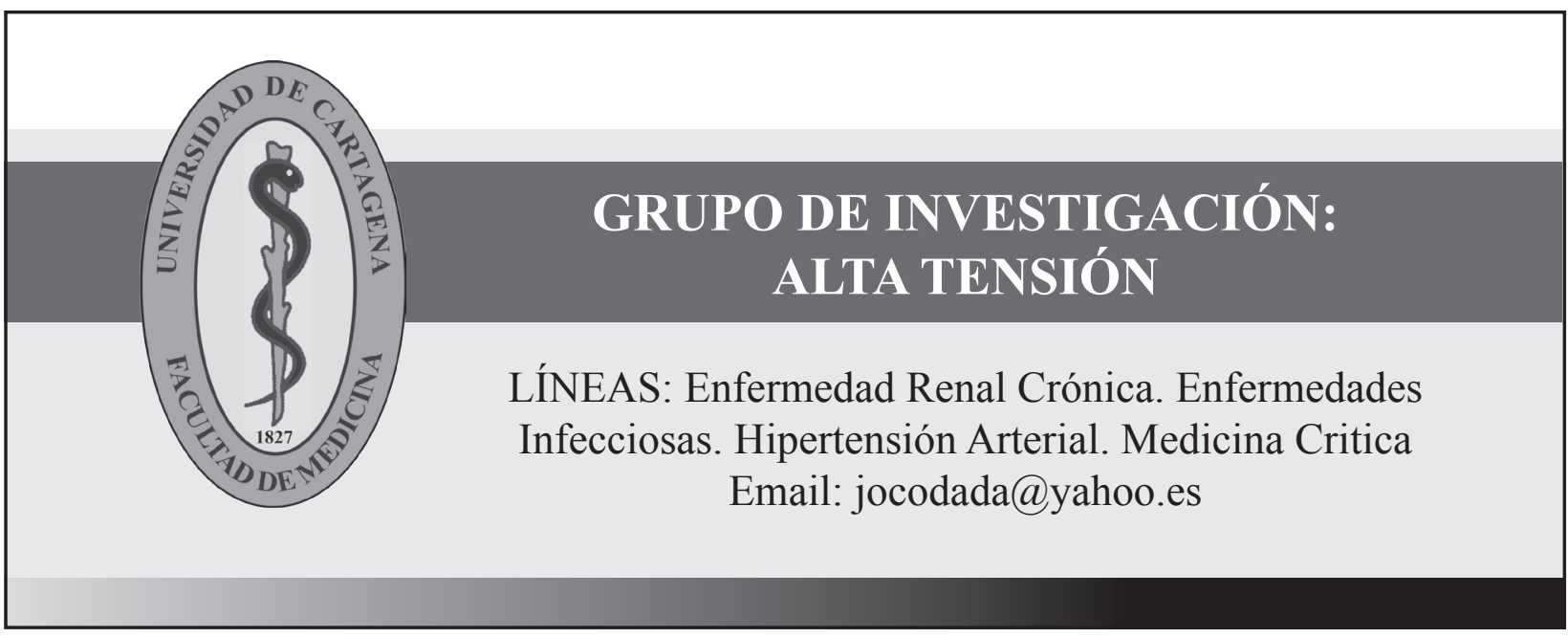

